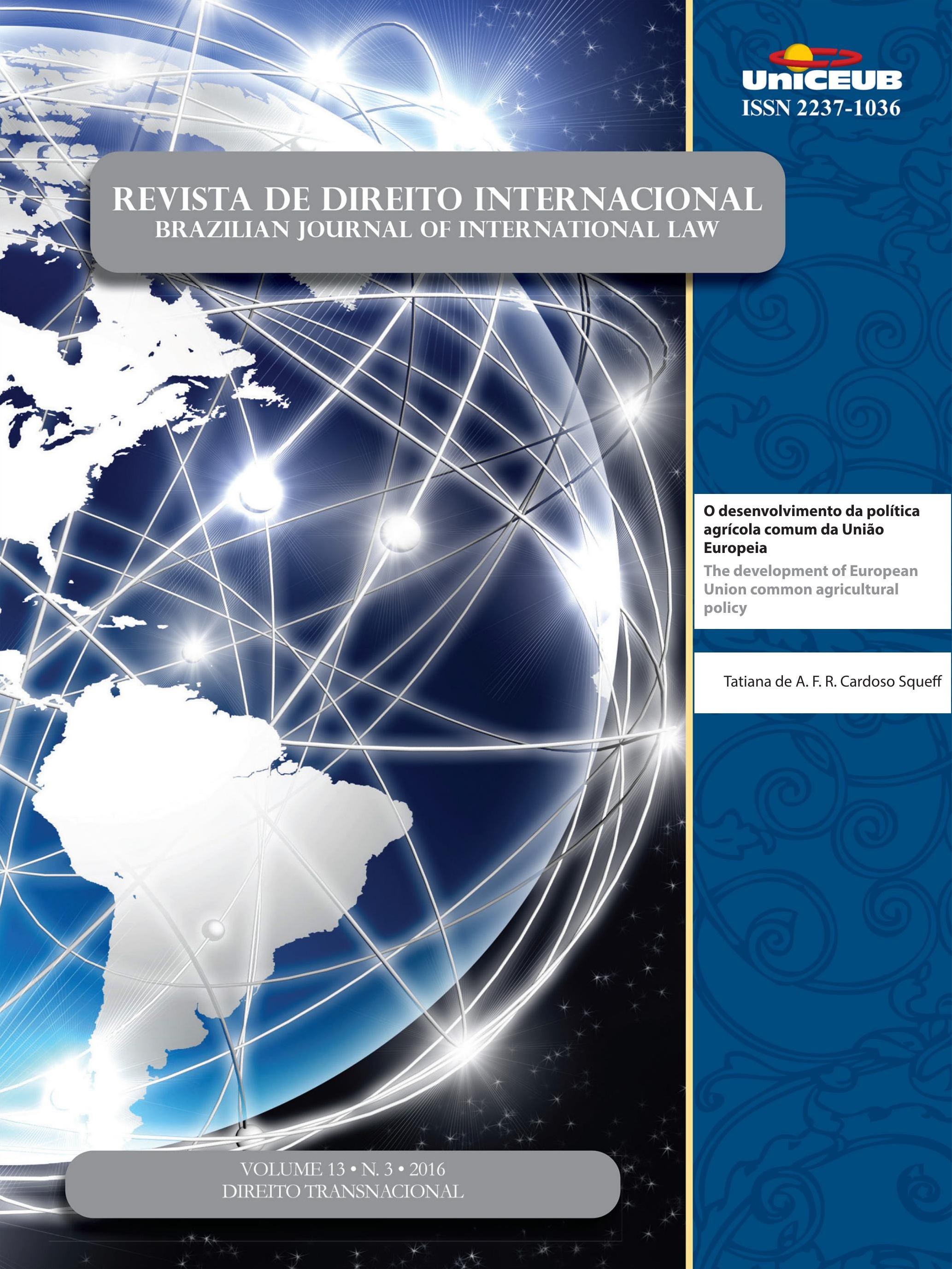


Crônicas da ATUALIdAde do direito internacional .................................................. 2

I. Dossiê Temático: Direito Transnacional .........................................................15

EDITORIAL: O Direito Transnacional - Circulação de normas e relações jurídicas transnacionais .......16 Priscila Pereira de Andrade

A emergênCia do direito transnacional ambiental .............................................18 Priscila Pereira de Andrade

Desafíos y RESPUESTAS TRANSNACIONALES FRENTE A LOS CRÍMENES AMBIENTALES ...............30 Rosmerlin Estupiñan-Silva

DiREITO TRANSNACIONAL E MUdANÇAS CLIMÁTICAS .50 Géraud de Lassus Saint-Geniès

Especies en movimiento: la Convención sobre el Comercio Internacional de Especies Amenazadas de Fauna y Flora Silvestres como espacio de “Encuentro” de discursos, ACTORES Y ESTRATEGIAS EN EL DERECHO AMBIENTAL TRASNACIONAL

María Valeria Berros e Dabel Leandro Franco

El carácter transnacional del Sistema comunitario de ECogestion « Eco-ManageMENT AND Audit SCHEME » (EMAS) DENTRo de LA UE y MÁs ALlÁ DE SUS Fronteras ......72 Adélie Pomade

O CONCEITO DE CONDUTA EMPRESARIAL RESPONSÁVEL À LUZ DOS ORDENAMENTOS JURÍDICOS BRASILEIRO, INTERNACIONAL E TRANSNACIONAL

Gabriel Webber Ziero

ARBITRAGEM NO DIREITO TRIBUTÁRIO INTERNACIONAL E NO DIREITO INTERNACIONAL DOS INVESTIMENTOS: UMA MANIFESTAÇÃO DO DIREITO TRANSNACIONAL

Vivian Daniele Rocha Gabriel 
O DIREITO TRIBUTÁRIO SOB UMA PERSPECTIVA TRANSNACIONAL

Franciele de Simas Estrela Borges

As Características do Direito Transnacional como Metodologia: Análise sob o enfoQue dos Aspectos Processuais da Arbitragem 126

Flávia Foz Mange

O DIREITO TRANSNACIONAL (“GLOBAL LAW") E A CRISE DE PARADIGMA DO ESTADO-CENTRISMO: É POSSÍVEL CONCEBER UMA ORDEM JURÍDICA TRANSNACIONAL? ...................................... 146

Luiza Nogueira Barbosa e Valesca Raizer Borges Moschen

TransPorte AÉREO E DIREITO TRANSNACIONAL: DA CONVERGÊNCIA À UNIFORMIDADE 160 Mickael R. Viglino

Outros Artigos. 175

O Fundo Monetário Internacional e a proteção dos direitos humanos: uma análise DO PROGRAMA DE CRESCIMENTO E REDUÇÃO DA POBREZA NO HAITI 177

Pablo Henrique Hubner de Lanna Costa e Carlos Alberto Simões de Tomaz

Um estranho no ninho? Padrões privados no Acordo de Barreiras Técnicas ao CoMÉRCIO DA OMC 192

Michelle Ratton Sanchez Badin e Marina Yoshimi Takitani

Os benefícios tributários do programa Inovar-Auto e os princípios da Nação Mais Favorecida e do Tratamento Nacional: uma análise dos argumentos dos Painéis atualmente em Curso contra o Brasil no Órgão de SoluÇão de Controvérsias da OMC . 211 Eric Moraes Castro e Silva

A ERA DA HUMANIDADE: REFLEXões PARA A HISTÓRIA DO DIREITO INTERNACIONAL 236 Henrique Weil Afonso

Precedentes vinculantes nos Estados Unidos da América e no direito brasileiro: Um ESTUDO COMPARADO 264

Patrícia Perrone Campos Mello 
IL DIRITTO AMBIENTALE SECONDO L'OTTICA DEL DIRITTO COSTITUZIONALE POSITIVO E LA RESPONSABILITÀ PER DANNI ALL'AMBIENTE NEL DIRITTO COMUNITARIO: LO STATO DELL'ARTE DEL DIRITTO AMBIENTALE COSTITUZIONALE E COMUNITARIO 287

Elcio Nacur Rezende

DA DESCONSIDERAÇÃo DA PERSONALIDADE JURÍDICA NAS RELAÇÕES CONSUMEIRISTAS BRASILEIRAS: ANÁLISE À LUZ DAS TEORIAS CLÁSSICAS

Daniel Amin Ferraz e Marcus Vinicius Silveira de Sá

ANALYSIS OF ADVANTAGES AND DISADVANTAGES OF FORUMS PRESCRIBED UNDER THE UNCLOS AND STATE PRACTICE: THE WAY AHEAD FOR INDIA ......................................................319

Vinai Kumar Singh

Do governo POR LEIS À governanÇA POR NúMERos: breve anÁlise do Trade in SERVICE AgreEMENT (TISA) ...............................................................................338 Jânia Maria Lopes Saldanha, Rafaela da Cruz Mello e Têmis Limberger

As DIRETIVAS EUROPEIAS COMO NORMA REGULADORA DO DIREITO ADMINISTRATIVO GLOBAL ..356 Alice Rocha da Silva e Ruth Maria Pereira dos Santos

O desenVolvimento da POlítica AGRícola COMUM dA UNião EUROPEIA 375 Tatiana de A. F. R. Cardoso Squeff

A imunidade de Jurisdição das organizaÇões internacionais FaCE AO Direito de aCESSO À JUSTIÇA 391

Fernanda Araújo Kallás e Caetano

O DIREITO INTERNACIONAL ENTRE O DEVER ÉTICO E A AÇÃo POLÍ́TICA: OS FUNDAMENTOS DE UM DEVER DE COOPERAÇÃO INTERNACIONAL NA FILOSOFIA POLÍTICA DE IMMANUEL KANT .405 Ademar Junior Pozzatti

EXTENSÃo E FRAGMENTAÇÃo NO CONTEXTO DA JURISDIÇÃO PENAL INTERNACIONAL .423 Marcus Vinícius Xavier de Oliveira

A DEFINiÇÃo JURÍdiCA DA "COMUNIDADE" .444 Nitish Monebhurrun, Michelle Lucas Cardoso Balbino, Fernanda Castelo Branco Araujo, Othon Pantoja, Míara Bogo Bruno e Cândida Dettenborn Nóbrega 
Comparative Study on Chinese Local Legislation of Science and Technology ProGRESS

LI Xiaoming e LI Yihan

O CONTROLE PENAL DO TRÁFICO DE PESSOAS: CONSTRUÇÃO JURÍDICA, INTERAÇÕES ORGANIZACIONAIS E COOPERAÇÃO INTERNACIONAL

Bruno Amaral Machado e Priscilla Brito Silva Vieira

Desativismo judicial: a extradição Battisti no Supremo Tribunal Federal .505 Francisco Rezek e Israel Paulino

A decisão norte-americana do Caso Myriad: novos paradigmas para a Proteção patenTÁRIA DO CÓDIGO GENÉTICO HUMANO E BIOTECNOLOGIA 514 José Carlos Vaz e Dias e Clarisse De La Cerda 


\title{
O desenvolvimento da política agrícola comum da União Europeia*
}

\author{
The development of European Union \\ common agricultural policy
}

\section{El desarrollo de la política agrícola común de la Unión Europea}

Tatiana de A. F. R. Cardoso Squeff**

\section{Resumo}

A Política Agrícola Comum - PAC - foi instituída com as Comunidades Econômicas Europeias a partir da adoção do Tratado de Roma em 1957 para a garantia da segurança alimentar no continente e é vista como um pilar básico da integração dessa região. O seu desenvolvimento decorre da própria evolução do bloco europeu, bem como da evolução do comércio internacional, exigindo outras/novas condutas por parte dos países europeus. Por isso, ao longo dos anos, a PAC sofreu diversas modificações estruturais importantes, as quais transformaram as formas em que o fomento agrícola é repassado aos agricultores, na tentativa de se tornar menos agressiva aos olhares da sociedade internacional. Assim, este artigo tem como objetivo abordar essas relações, desde a importância da agricultura para a formação da União Europeia, como também as modificações inseridas na PAC em virtude nos novos arranjos regionais e mundiais.

Palavras-chave: Política Agrícola Europeia; Integração; Segurança Alimentar.

* Recebido em 06/10/2016 Aprovado em 07/12/2016

** Doutoranda em Direito Internacional pela UFRGS (2014). Mestre em Direito Público pela Unisinos, com fomento CAPES (2012). Especialista em Relações Internacionais pela UFRGS (2015), em Direito Internacional pela UFRGS (2009) e em Língua Inglesa pela Unilasalle (2008). Pesquisadora convidada da Universidade de Toronto/Canadá. Professora de Direito Internacional e Relações Internacionais da graduação em Direito do UniRitter e da Unifin. Professora substituta da Faculdade de Dirieto da UFRGS. E-mail: tatiana.cardoso@ufrgs.br

\section{Abstract}

The Common Agricultural Policy - CAP - was established with the European Economic Community by the adoption of the Treaty of Rome in 1957, in order to ensure the continent's food security, being it a basic pillar to this region's integration. Its development follows the evolution of the European Bloc as well as the changes in international trade, requiring other/ new behaviors by the European countries. Thus, over the years, the CAP has undergone several significant structural changes, which have transformed the way subsidies are passed on to farmers, in an attempt to become less aggressive to the eyes of international society. Hence, this paper aims to address these topics, from the importance of agriculture to the European Union establishment to the changes inserted into the CAP due to new regional and global arrangements. 
Keywords: European Agricultural Policy; Integration; Food Security.

\section{Resumen}

La Política Agrícola Común - PAC - se estableció con la Comunidad Económica Europea con la adopción del Tratado de Roma en 1957, con el fin de garantizar la seguridad alimentaria del continente, siendo un pilar básico de la integración de esta región. Su desarrollo sigue la evolución del bloque europeo, así como los cambios en el comercio internacional, los cuales requieren otros/nuevos comportamientos de los países europeos. De este modo, a lo largo de los años, la PAC ha sido objeto de varios cambios estructurales significativos, que han transformado la forma en que se transmiten los subsidios a los agricultores, en un intento de ser menos agresiva bajo los ojos de la sociedad internacional. Por lo tanto, este trabajo procura abordar estos temas, desde la importancia de la agricultura para el establecimiento de la Unión Europea hasta los cambios introducidos en la PAC debido a los nuevos acuerdos regionales y globales.

Palabras--clave: Política Agrícola Europea; Integración; Seguridad Alimentaria.

\section{INTRODUÇÃo}

A União Europeia (UE) intervém em vários domínios econômicos, sendo a Agricultura um dos mais relevantes. Afinal, essa foi uma área bastante prejudicada com a Segunda Guerra Mundial, sendo necessária uma atuação mais forte por parte do bloco a fim de evitar os riscos decorrentes da falta de alimentos.

A política de agricultura, por força disso, foi criada para assegurar e promover a produção de alimentos, sendo considerada uma "política de reserva", já que ela tem como objetivo proteger o mercado intrabloco por intermédio de uma série de medidas de salvaguardas em detrimento de previsões externas e/ou internacionais. Ocorre que essa política vem se modificando ao longo dos anos em virtude nos novos arranjos regionais e mundiais, impactando, diretamente, o comércio internacional, sobretudo, por manipular os preços e a própria produção.
Assim, o presente artigo tem como o objetivo explanar a criação da Política Agrícola Comum (PAC), traçando seus principais objetivos e as suas transformações ao longo dos anos culminando na atual prática aplicada no plano europeu. De modo mais explícito, as principais perguntas que permeiam o presente escrito são quais os motivos que levaram os europeus a construírem uma política comunitária atinente às questões agrícolas e como se deu o seu desenvolvimento ao longo dos anos.

A fim de responder aos questionamentos propostos, o escrito será subdivido em três segmentos: o primeiro destacando a importância da agricultura para a construção da União Europeia; o segundo abarcando a contextualização histórica da questão agrícola na Europa, a fim de ressaltar a importância do setor agrícola ao longo dos anos, bem como as suas modificações; e o terceiro contemplando o desenvolvimento da PAC em si, expondo a forma em que se dá a sua aplicação, bem como as instituições europeias envolvidas nessa atividade.

Quanto à justificativa para essa abordagem, tem-se que esta é necessária a fim de compreenderem-se os motivos que levam a Europa a adotar discursos protetivos no âmbito das negociações comerciais internacionais, como também as dificuldades atinentes ao próprio comprometimento desse bloco quando da adoção de um compromisso mais liberalizante, em função das previsões do direito comunitário. Por fim, no que diz respeito aos aspectos metodológicos, utilizando-se do método dedutivo e com o auxílio de dados econômicos, documentos institucionais e da própria literatura jurídica e político-econômica existente sobre o tema, será realizada uma análise descritiva acerca da formação e da aplicação da Política Agrícola Comum europeia.

\section{A agricultura como política INTEGRACIONISTA dA UNIão EUROPEIA}

O contexto em que o tema da integração emerge é, justamente, na tentativa de manter-se a paz entre as diferentes nações. Partindo-se do pressuposto kantiano de que o estado de natureza de quaisquer relações existentes é o da guerra e de que a única forma de se conter essa ameaça seria por meio da criação de estruturas jurídicas que possibilitem a segurança necessária para a vida em sociedade de forma pacífica, é impossível negar a 
importância que a aproximação entre os Estados exerce para a promoção da paz.

Por conseguinte, os Estados criam regras as quais norteiam suas relações em sociedade, aproximando-se uns aos outros na tentativa de constituir uma sociedade universal pacífica. Até mesmo, a partir do arcabouço teórico elucubrado por $\mathrm{Kant}^{1}$, torna-se ainda mais plausível o comércio internacional, Como revela o referido autor, o direito cosmopolita "tem a ver com a possível união de todas as nações com vistas a certas leis universais para o possível comércio entre elas".

E a União Europeia (UE) é a expressão desse contexto. Muito embora se trate de um número reduzido de países quando comparado à totalidade mundana, ao longo da história, é possível visualizar momentos de enorme evolução comercial quando havia paz nas relações das nações europeias, como aquele que se constrói a partir do Concerto Europeu estabelecido em 1815 ao final do Congresso de Viena. ${ }^{2}$ Isso, pois, como aduz Maria Odete Oliveira, "no século XIX, a economia europeia desenvolveu interessante grau de integração, firmando tratados comerciais para resolver as discriminações entre os Estados, como de França e Grã-Bretanha"3, e pela "unificação dos territórios aduaneiros dos Estados germânicos [...], formando a Deutscher Zollverein" - nome atribuído à União Aduaneira constituída ainda em 1834, como ressalta Marcelo Bohkle.

Entretanto, os períodos de guerra mostraram-se verdadeiros retrocessos a essa perspectiva integracionista, uma vez que motivados pelo nacionalismo exacerbado, acabam por promover o protecionismo e a rivalidade - fatos que vão de encontro com o processo de aproximação (pacífica) das nações. Exemplo disso são as duas guerras mundiais que assolaram a humanidade no século XX, trazendo grande prejuízo à sociedade internacional, o que inclui a economia europeia por gerarem graves crises de pagamentos e inibições ao comércio. ${ }^{5}$

1 KANT, Immanuel. A Metafísica dos Costumes. Trad. Edson Bini. São Paulo: Edipro, 2003, p. 194.

2 KOZOLCHYK, Boris. Comparative Commercial Contracts: law, culture and economic development. St. Paul: West Academic Pub., 2014, p. 379-380.

3 OLIVEIRA, Maria Odete. União Europeia: processos de integração e mutação. Curitiba: Juruá, 2005, p. 31.

4 BOHKLE, Marcelo. O processo de Integração Regional e a Autonomia do seu Ordenamento Jurídico, 2002, 264 fls. Dissertação - Mestrado em Direito. Florianópolis: Universidade Federal de Santa Catarina, 2002, p. 21.

5 Acerca da Primeira Guerra Mundial, o Tratado de Versalhes im-
Cenário esse que se transforma, novamente, com a edificação ainda em 1944 da União Aduaneira ${ }^{6}$ formada por Bélgica, Holanda e Luxemburgo (BENELUX) ${ }^{7}$, bem como pela construção da Comunidade Europeia do Carvão e do Aço (CECA) em Paris no ano de 1951 como forma de se preservar a paz no continente ${ }^{8}$, os quais reascenderam o ideário de integração que viria a ser lapidado na Europa a partir de então. ${ }^{9}$

A partir desses desdobramentos, a proposta de integração toma outras proporções: para além da garantia da paz (propiciada pelo controle de energia - carvão e aço), busca-se "a fusão dos mercados e a expansão da produção", fazendo com que outros acordos fossem firmados em 1957 na Itália na tentativa de aproximar ainda mais os seus membros ${ }^{10}$. Os Tratados de Roma, por conseguinte, dão origem à Comunidade Econômica Europeia (CEE) e à Comunidade Europeia da Energia Atômica (CEEA/EURATOM) ${ }^{11}$

Com essas instituições, a integração econômica deixa de ter, apenas, um caráter interestatal, passando efe-

pôs diversas restrições aos derrotados, como no caso alemão de perder territórios na África e de ressarcir vítimas - isso sem contar os percalços do período entre guerras que levariam a queda do liberalismo, como a Crise de 1929. Quanto a Segunda Guerra, essa deixou a Europa em frangalhos, haja vista a economia de guerra não ser voltada para suprir as necessidades comerciais domésticas. HOBSBAWN, Eric. The Age of Extremes: a history of the world 19141991. New York: vintage books, 1994, p. $98-99$ (sobre a Primeira Guerra) e 240 (sobre a Segunda Guerra); Cf. também: JAEGER JUNIOR, Augusto. Mercados Comum e Interno e Liberdades Econômicas Fundamentais. Curitiba: Juruá, 2010, p. 47-48.

6 União Aduaneira (UA) é o segundo nível que pode ser atingido em um processo de integração regional, onde além de oferecer concessões comerciais generalizadas, estipula-se uma Tarifa Externa Comum (TEC). Cf. BAUMANN, Renato; CANUTO, Otaviano; GONÇALVES, Reinaldo. Economia Internacional: teoria e experiência brasileira. Rio de Janeiro: Campus, 2004, p. 106-107.

7 Note-se que o BENELUX entrou em vigor em meados de 1948 com a assinatura de um protocolo adicional em Haia no ano anterior (1947). BOHKLE, op. Cit., p. 22.

8 Constituída pelos integrantes do BENELUX, além de Alemanha, França e Itália (formando a "Europa dos seis"), a CECA entrou em vigor em julho de 1952. JUNQUEIRA, Bráulio. A Institucionalização Política da União Europeia. Coimbra: Almedina, 2008, p. 115.

9 Ibidem, p.112-115; CARNEIRO, Cynthia S. O Direito da Integração Regional. Belo Horizonte: Del Rey, 2007, p. 80; JAEGER JUNIOR, op. cit., p. 47 [Para o autor, os Planos Marshall e Molotov também influenciaram a integração europeia. O primeiro por impulsionar a criação da Organização Europeia de Cooperação Econômica - OECE - em 1947; já o segundo, por ser lançado aos países do leste europeu, fomentando a divisão interna do continente, guardando relação íntima com o quinto alargamento da UE de 2004].

10 JAEGER JUNIOR, op. cit., p. 48-49.

11 CARNEIRO, op. cit., p. 81. 
tivamente a confecção de um projeto comunitário para além do Estado nacional. Acerca disso, merece destaque as palavras de Augusto Jaeger Júnior:

O momento da assinatura dos tratados representou o desejo de um bem-estar econômico, segurança e um construtivo da Europa na política mundial. [...] Criava-se, com isso, mais duas entidades supranacionais, diferentes das organizações internacionais tradicionais, pois representavam mais que uma simples cooperação interestatal. ${ }^{12}$

Com esses tratados restou "institucionalizado o programa para se criar, gradativamente, um mercado comum $^{13}$ na Europa Central visando a livre circulação de todos os fatores de produção: trabalhadores, mercadorias, serviços e capital"14, além da própria concorrência $^{15}$. E, conforme pondera Augusto Jaeger Junior ${ }^{16}$, muito embora a CEEA possuísse uma limitação setorial (a nuclear), a CEE não estava adstrita a uma área em especial, abrangendo "todos os ramos da economia entre os Estados-membros e as suas relações com Estrados terceiros", tendo, por isso, alcançado "um maior significado".

Aliás, é no Tratado da Comunidade Econômica Europeia que está assentada a necessidade de criar-se uma série de políticas comunitárias voltadas aos diversos campos da economia, buscando a padronização de ações em prol da edificação de um mercado único na região. ${ }^{17}$ Afinal, sem a adoção de políticas comuns específicas,

[...] o funcionamento da União Aduaneira e o exercício das liberdades consagradas nos Tratados poderiam conduzir a graves distorções, desiquilíbrios nas trocas ou tensões económicas [sic] capazes de impedir ou, pelo menos, prejudicar seriamente a realização da pretendida integração europeia. ${ }^{18}$

Dentre as Políticas Comuns estão as relativas ao Comércio (artigos 110 a 116), ao Transporte (artigos 74 a 84) e à Agricultura (artigos 38 a 47$)^{19}$ - essa última,

\section{Ibidem, p. 50.}

13 Mercado Comum é o terceiro nível que pode ser atingido em um processo de integração regional, o qual consiste em uma "UA acrescida de plena mobilidade de fatores de produção entre os países participantes". BAUMANN; CANUTO; GONÇALVES, op. cit., p. 107.

14 CARNEIRO, op. cit., p. 81.

15 JAEGER JUNIOR, op. cit., p. 221-251.

16 Ibidem, p. 51.

17 OLIVEIRA, op. cit., p. 201.

18 CAMPOS, João Mota de. Manual de Direito Comunitário. $2^{a}$ ed. Curitiba: Juruá, 2013, p. 480

19 UNIÃO EUROPEIA. Tratado Constitutivo da Comuni- além de ser o objeto central do presente estudo, é, sem dúvida, uma das mais importantes para que se atinja um mercado único, haja vista as próprias diferenças entre os seis países europeus no que tange à produtividade agrícola, os preços e os custos de produção ${ }^{20} .{ }^{21}$

Por isso, conforme o próprio Tratado de Roma determina, a agricultura é compreendida como um vetor central para a integração europeia, a qual, ao seu turno, era imperiosa para a manutenção da paz no continente. Entretanto, a pergunta que paira a partir dessa colocação é, justamente, o porquê da agricultura figurar como um setor importante, cuja resposta está justamente na garantia da segurança alimentar - tema esse que será abordado na seção subsequente.

\section{A IMPORTÂNCIA INICIAL DO SETOR AGRÍCOLA NO ÂMBITO COMUNITÁRIO: A GARANTIA DA SEGURANÇA ALIMENTAR}

O setor agrícola foi visto como estrategicamente relevante para o bloco, uma vez que, como informa Arlindo Cunha ${ }^{22}$, a agricultura, ao final da década de 1950, representava "mais de $25 \%$ do emprego total e quase $10 \%$ do Produto Interno Bruto" (PIB). Em alguns países participantes da Europa dos seis, o número doméstico era bem expressivo, tal como na França, onde $27 \%$ da população economicamente ativa situava-se na zona rural, o que representava $11 \%$ do PIB francês; e na Itália, onde os números eram ainda maiores: 40\% da população economicamente ativa estava nos campos, representando $20 \%$ do PIB italiano. ${ }^{23}$

dade Econômica Europeia. 1957.

20 Cf. tabelas completas em: U.S. DEPARTMENT OF AGRICULTURE. Indices of Agriculture Production in Western Europe - 1650-1968. Washington D.C.: US Department of Agriculture, 1969. Disponível em: <https://archive.org/stream/ indicesofagricul266unit\#page/n1/mode/2up > . Acesso em: 02 fev. 2015.

21 Importante dizer que diversas políticas comuns ao longo dos anos vão surgindo, por exemplo, na área de segurança e, até mesmo, sobre pescas. Acerca dessa última, inclusive, cf. LAUREANO, Abel; RENTO, Altina. Uma sumária radiografia da política comum das pescas da União Europeia. Revista de Direito Internacional, Brasília, v. 9, n. 3, 2012, p. 71-90.

22 CUNHA, Arlindo. A Política Agrícola Comum na Era da Globalização. Coimbra: Almedina, 2004, p. 13.

23 CARISIO, Maria Clara D. A Política Agrícola Comum da União Europeia e seus Efeitos Sobre os Interesses Brasileiros nas Negociações Internacionais Sobre Agricultura. Brasília: FUNAG, 2006, p. 22 e 27. 
Apesar disso, tanto os alimentos (produção e abastecimento) quanto a economia rural (infraestrutura) foram áreas fortemente atingidas pelos grandes acontecimentos da primeira metade do século XX, especialmente ao final da Segunda Guerra Mundial. ${ }^{24}$ Em meio às possibilidades integracionistas que eram discutidas, a população europeia sofria com a falta de alimentos, seja ela na quantidade, na qualidade e/ou na regularidade de acesso. $^{25}$

Ademais, com informa José Pedro Fernandes ${ }^{26}$, "para além da questão do autoabastecimento [sic], o défice de produção agrícola tinha reflexos negativos na balança comercial" europeia, gerando mais dívidas ao continente que se via obrigado a importar alimentos, os quais possuam preços variáveis por força do mercado internacional. Visualizou-se, a partir desse contexto, a evidente necessidade da Europa em buscar autossuficiência alimentar, modernizar a zona rural e melhorar as condições de vida da população rural. Afinal, como exprime Maria Auxiliadora Carvalho ${ }^{27}$, "os governos reconheciam que a carência de alimentos no pós-Segunda Guerra era uma situação delicada para a sobrevivência da população", sobretudo, em função de a história europeia estar "repleta de revoltas, conflitos, migrações e invasões causadas, em última análise, pela fome endêmica, epidêmica ou cíclica (sazonal)", como diria Álvaro Gurgel de Alencar ${ }^{28}$.

Logo, em função da (i) importância econômica que o setor agrícola representava, (ii) do valor variável das commodities recorrentemente importadas e (iii) do impacto social que os alimentos apresentam, a agricultura não poderia restar de fora de uma estruturação regional. ${ }^{29}$ A PAC, por sua vez, era o instrumento central que

24 CARVAlHO, Maria Auxiliadora. Políticas Públicas e Competitividade de Agricultura. Revista de Economia Política, São Paulo, v.21, n. 1, pp. 117-140, jan./mar. 2001, p. 124.

25 SANTOS, Francis. Perspectiva para a soberania alimentar brasileira. In: DAL SOGLIO, Fábio; KUBO, Rumi Regina (coords.). Agricultura e Sustentabilidade. Porto Alegre: Editora da UFRGS, 2009, p. 118.

26 FERNANDES, José Pedro. Elementos de Economia Política Internacional. $2^{a}$ ed. Coimbra: Almedina, 2012, p. 154.

27 SILVA, Daniel P.; FERREIRA, Grace K. A Política Agrícola Comum da União Europeia. Fronteira. Belo Horizonte, v. 7, n. 14, pp.65-76, 2008, p. 72.

28 ALENCAR, Álvaro Gurgel de. Do conceito estratégico de segurança alimentar ao plano de ação da FAO para combater a fome. Revista Brasileira de Política Internacional, Brasília, v. 44, n. 1, pp. 137-144, 2001, p. 139.

29 Vale dizer, essas três razões (somadas à impossibilidade de diferenciar produtos agrícolas e industriais) já haviam sido realçadas viabilizaria esse objetivo. No artigo 39 do Tratado de Roma que constituíra a CEE, estavam presentes os fins a serem perseguidos pela PAC, quais sejam:

a) Incrementar a produtividade da agricultura, fomentando o progresso técnico, assegurando o desenvolvimento racional da produção agrícola e a utilização óptima dos fatores de produção, designadamente da mão-de-obra;

b) Assegurar, deste modo, um nível de vida equitativo à população agrícola, designadamente pelo aumento do rendimento individual dos que trabalham na agricultura;

c) Estabilizar os mercados;

d) Garantir a segurança dos abastecimentos;

e) Assegurar preços razoáveis nos fornecimentos aos consumidores. ${ }^{30}$

Como é possível observar, esses objetivos estabelecem mais orientações do que procedimentos e operações $\operatorname{diretas}^{31}$; porém, como aduz Maria Odete Oliveira ${ }^{32}$, eles abarcam não apenas "a agricultura propriamente dita e o comércio de seus produtos como uma política comum [...] visando ao funcionamento e desenvolvimento do mercado" agrícola como um todo, preocupando-se com a cadeia completa - desde os agricultores aos consumidores, sem olvidar da qualidade e quantidade dos alimentos disponíveis a nível intracomunitário.

Para que fossem atingidas as finalidades, transferiram-se as competências referentes à agricultura para as instituições comunitárias, especificamente as Organizações Comuns de Mercado $^{33}$ (OCM), fazendo com que estas pudessem tomar todas as medidas necessárias para a consecução dos objetivos delineados no Tratado, tais como (i) a regulação de preços, (ii) a implementação de subsídios à produção e à comercialização de produtos, ou, até mesmo, (iii) a criação de mecanismos para estabilizar as importações e exportações. ${ }^{34}$

no Relatório Spaak, apresentado ainda em 1956, o qual "lançou as bases da futura Comunidade Econômica Europeia”. CARISIO, op. cit, p. 34.

30 UNIÃo EUROPEIA. Tratado Constitutivo da Comunidade Econômica Europeia. 1957. Art. 39(1).

31 CARISIO, op. cit, p. 35.

32 OLIVEIRA, op. cit, p. 202.

33 Em 2007, a partir do Regulamento n. ${ }^{\circ} 1234$, de 16 de novembro, as 21 OCMs então existentes fundiram-se em uma única OCM. Para mais detalhes quanto a atuação e até mesmo quanto ao orçamento disponível, cf.: PARLAMENTO EUROPEU. Fichas Técnicas sobre a União Europeia: Primeiro pilar da PAC. Nota veiculada em mar. 2014. Disponível em: <http://www.europarl.europa.eu/aboutparliament/ pt/displayFtu.html?ftuId=FTU_5.2.4.html >. Acesso em 03 fev. 2015. 34 UNIÃO EUROPEIA. Tratado Constitutivo da Comuni- 
Note-se que, com a instituição gradativa das OCMs, o processo de integração dava passos largos, uma vez que o processo decisório era confiado à instituições supranacionais (nomeadamente à Autoridade Comunitária, isto é, à Comissão e ao Conselho criados pelo Tratado de 1957). ${ }^{35} \mathrm{E}$, com o fito de incrementar, especificamente, a consolidação do Mercado Agrícola Comum, foi realizada, em 1958, na cidade italiana de Stres$s a$, uma conferência entre os seis Estados-parte da CEE, em que as políticas de cada país quanto aos recursos e as necessidades do setor foram comparadas e debatidas. ${ }^{36}$

Dessa reunião nasceram os três princípios gerais que guiariam a aplicação da PAC a partir de 1962. São eles: (i) a unicidade do mercado, advogando pela livre circulação de produtos agrícolas na Comunidade, eliminando-se quaisquer tipos de barreiras comerciais existentes; (ii) a preferência comunitária, protegendo e fomentando o mercado interno por meio do estabelecimento de um sistema de preços fixos ${ }^{37}$ para os produtos intracomunitários e da imposição de restrições (como sobretaxas aduaneiras) aos produtos importados; e (iii) a solidariedade financeira, criando um sistema comunitário de financiamento - o Fundo Europeu de Orientação e de Garantia Agrícola (FEOGA) - para as despesas oriundas da aplicação da política agrícola. ${ }^{38}$

dade Econômica Europeia. 1957. Art. 40(2) e 40(3).

35 Maria Odete de Oliveira, citando Molina Ibañez e Rodrigues Pose, exemplifica a importância da criação das OCMs para a integração a partir da OCM para os cereais (estipulada em 1962), pois, em oito anos de atuação, já detinha $87 \%$ da produção intracomunitária sob seu comando (porém, sem excluir a colaboração das entidades nacionais competentes). MOLINA IBAÑEZ, M.; RODRIGUES POSE, A. Transformaciones Agrarias em la Europa Comunitária. Salamanca: Universidad de Salamanca, 1992, p. 699 apud OLIVEIRA, op. cit, p. 202.

36 Essa conferência e os seus objetivos estavam previstos no próprio Tratado de Roma. UNIÃO EUROPEIA. Tratado Constitutivo da Comunidade Econômica Europeia. 1957. Art. 43(1).

37 Os preços fixos, na inexistência do EURO, sofriam com as variações cambiais, sendo necessária a criação de um sistema - o green money - pela Comissão para compensar as taxas flutuantes. CARISIO, op. cit, p. 38.

38 CUNHA, op. cit, p. 14 e 24-25; OLIVEIRA, op. cit, p. 203-207; CARISIO, op. cit, p. 36; CAMPOS, op. cit, p. 482-484 [Cumpre destacar que esse último autor subdivide os princípios norteadores em quatro, adicionado à política de estruturas, a qual se referiria a criação de uma política comum de estruturas para ajudar financeiramente e intelectualmente aqueles diretamente envolvidos à atividade agrícola a fim de equiparar as condições para o desenvolvimento da agricultura, evitando-se, assim, a concorrência desleal e os custos excessivos à Comunidade. Para os outros autores, esses fins encaixam-se tanto ao princípio da unicidade do mercado, pois essas peculiaridades seriam barreiras ao comércio intrabloco, quanto da solidariedade financeira, uma vez que essa estaria dividida em duas seções - uma
Esses pressupostos, portanto, indicavam o viés protecionista europeu ao seu mercado agrícola. O cenário arquitetado não previa perdas para o agricultor e consumidor $^{39}$, mas sempre um jogo de soma positiva (muito embora negativos para a comunidade em função do financiamento concedido, o qual girava na casa de $60 \%$ do orçamento ${ }^{40}$ ). Afinal, como explicam Jacques Loyat e Yves Petit ${ }^{41}$, era garantida a compra da produção ao produtor, o que estabilizava os preços dos produtos, eliminava quaisquer possibilidades de concorrência entre os diferentes produtores intrabloco e, ainda, fazia com que a produção aumentasse mesmo sem a demanda. Isso porque, com o sistema de preços preestabelecidos ${ }^{42}$ (conhecido como 'preço de intervenção'), permitiam-se altos ganhos aos produtores, já que lhes era pago pela Comunidade o valor fixo acertado pelas OCMs - e não o de mercado. ${ }^{43}$

O progresso foi tamanho que a tão esperada segurança alimentar foi atingida em pouquíssimo tempo. Produtos de primeira necessidade (como cereais, batata e laticínios) eram abundantes. Nas palavras de José Eli da Veiga ${ }^{44}$, "a recuperação do setor agrícola dos países europeus foi rapidíssima", de modo que a produção ultrapassou em 50\% os níveis do pré-Segunda Guerra graças à política de sustentação de preços.

Por intermédio da PAC, portanto, é que se pode afirmar que a Europa passou a ser uma região soberana no campo alimentar, uma vez que, por meio dela, restaram definidas uma série de "políticas e estratégias sustentáveis de produção, distribuição e consumo de alimento que garantem o direito à alimentação para toda a população", como bem apontaram Carla Rosane P.

orientada ao desenvolvimento rural e outra à garantia dos mercados, comprando excedentes e provendo subsídios para a exportação].

39 OLIVEIRA, op. cit, p. 206.

40 CARMO, Luis Antônio A. A vertente aduaneira da Política Agrícola Comum. In: TEIXEIRA, Glória. Direito Rural (coord.). Porto: Vida Econômica, 2013, p. 316

41 LOYAT, Jacques; PETIT, Yves. La Politique Agricole Commune (PAC): une politique en mutation. 3a ed. Paris: La Documentation Française, 2008, p. 12.

42 Por exemplo, o trigo era vendido $91 \%$ a mais sobre o valor da Bolsa de Chicago, o milho a $87 \%$ a mais sobre o valor da Bolsa de Chicago e o açúcar a expressivos 338\% a mais que a cotação da Bolsa de Londres. ESPINOSA, Jaime L. La Nueva Política Agraria de la Unión Europea. Madrid: Ediciones Encuentro, 1998, p. 43. 43 Ibidem, p. 11-12; CAMPOS, op. cit., p. 483; CUNHA, op. cit., p. 16; FERNANDES, op. cit., p.175.

44 VEIGA, José Eli da. O Desenvolvimento Agrícola: uma visão histórica. $2^{a}$ ed. São Paulo: Edusp, 2007, p. 135. 
Teo e Lucinada S. Gallina ${ }^{45}$. E não apenas isso, com essa segurança alimentar, a própria paz - entendida como chave para a integração - estaria garantida, pois a política agrícola aproximaria dos seis países e unificaria as suas ações para evitar outros problemas que a falta de alimentos poderia ocasionar.

Outrossim, a PAC sofreria diversas transformações ao longo dos anos, sobretudo, em razão da aproximação de outros países, os quais juntar-se-iam aos seis formado a União Europeia e do desenvolvimento do plano econômico internacional, cujas exigências cada vez mais estariam na liberalização do comércio, em detrimento de políticas protecionistas - possibilidades essas a serem debatidos na próxima subseção.

\section{A política agrícola COMUM fRente aOS NOVOS ARRANJOS SOCIOECONÔMICOS REGIONAIS E MUNDIAIS: ENTRE A CONSERVAÇÃO E A REESTRUTURAÇÃO}

Se, por um lado, a PAC, em seus primeiros anos, permitiu o fornecimento "de produtos de qualidade a preços acessíveis, a modernização dos meios de produção e a multiplicar a produtividade", tal como anota Danielle Bianchi $^{46}$, note-se que ela, igualmente, gerou um grande excedente de produção. Por essa razão, de acordo com Arlindo Cunha ${ }^{47}$, houve o "disparo dos custos orçamentais (que entre 1960 e 1970 foram multiplicados por seis)" pela crescente necessidade de se intervir no mercado para comprar (e estocar) o excedente e de subsidiar à exportação ${ }^{48}$.

Apesar disso, a economia mundial parecia absorver bem esse excedente, mormente em função do rápido

45 TEO, Carla Rosane Paz; GALLINA, Lucinada S. Segurança Alimentar e Ambiente: a sustentabilidade como área de convergência. In: SÁ, Clodoaldo de; FERRETI, Fátima; BUSATO, Maria Assunta. Ensaios Contemporâneos em Saúde. Chapecó: Argos, 2013, p. 67. 46 BIANCHI, Danielle. La Politique Agricole Commune (PAC): toute la PAC, rien d'autre que la PAC! Bruxelles: Bruylant, 2006, p.17.

47 CUNHA, op. cit., p. 16-17.

48 Acerca da substituição de importação, cf.: FERNANDES, op. cit., p.176; ARANHA, Maria Marcele A. A Política Agrícola Comum e a Disciplina do Apoio Interno do Acordo sobre Agricultura da Rodada do Uruguai. Coimbra: Coimbra Ed., 2007, p. 102-104; ADAM, Valérie. La Reforme de la Politique Agricole Commune de L'Union Europeenne. Paris: Editions L'Harmattan, 2001, p. 18. crescimento da população nos países em desenvolvimento e pelo crescimento econômico mundial, o qual restava na ordem de $8 \% .{ }^{49}$ Ocorre que, com a escalada da demanda, os preços dos produtos agrícolas diminuíam internacionalmente, forçando a Europa a intervir, cada vez mais, no setor em virtude do sistema de preços preestabelecidos, seja para pagar ao produtor, seja para subsidiar a exportação das commodities.

Esse cenário preocupante fez com que o comissário responsável pela agricultura europeia no período, Sicco Mansholt, propusesse em 1968 uma série de medidas para contornar a situação, as quais restaram mais conhecidas como Plano Mansholt. ${ }^{50}$ A seu ver, dever-se-ia (i) reduzir do número de trabalhadores agrícolas, favorecendo, inclusive, a aposentadoria; (ii) promover a formação de unidades produtivas mais eficientes, eliminando-se os intermediários; (iii) ampliar as áreas protegidas, criando-se bosques; (iv) possibilitar a qualificação dos agricultores; e, finalmente, (v) diminuir os preços para uma menor intervenção no mercado - propostas essas que foram, inicialmente, rechaçadas pelo Conselho em virtude das pressões nacionais. ${ }^{51}$

Dessas sugestões, apenas quatro obtiveram sucesso nos anos seguintes, dando origem às Diretivas de número 72/159 (atrelada à modernização das propriedades rurais), a 72/160 (relativo à possibilidade de abandono por parte dos agricultores idosos), 72/161 (ligada ao aprimoramento técnico dos agricultores) e 75/268 (promovendo a agricultura de montanha e de áreas desfavorecidas).$^{52}$ Muito embora não sejam classificadas como reformas, essas regras comunitárias pretendiam adaptar a PAC àquilo que se considerava ideal com base no atual cenário comunitário e internacional.

Afinal, não se pode esquecer que, no âmbito europeu, em 1971 houve o primeiro alargamento do Bloco com a inclusão de Dinamarca, Irlanda e Reino Unido, o que gerou grandes controvérsias, especialmente, em

49 ARANHA, op. cit., p. 18-19; PLATERO, Roberto Velasquez. Inversión y Mecanismos para la Movilizacion de Recursos Financieros para la Agricultura. San José: Inst. Interamericando de Coop. Para la Agricultura, 1989, p. 14.

50 OLIVEIRA, op. cit., p. 207.

51 ESPINOSA, op. cit., p. 43-44; CUNHA, op. cit., p. 17; ABELLÁN, Aurelio C. Las Regiones del Sistema Mundo. Murica: Universidad de Murica, 1993, p. 38.

52 COMISSÃO EUROPEIA. History of the CAP: the crisis years I - the 1970s. s/d. Disponível em: <http:/ / ec.europa.eu/agriculture/cap-history/crisis-years-1970s/index_en.htm>. Acesso em 03 fev. 2015; CUNHA, op. cit., p. 18; ESPINOSA, op. cit., p. 44. 
razão da inaplicabilidade inicial do princípio da solidariedade financeira aos ingleses, afetando diretamente o orçamento do FEOGA. ${ }^{53}$ Ao mesmo tempo, internacionalmente, a crise econômica ${ }^{54}$ que se alastrou em meados da década de setenta acabou por fortalecer a tese do protecionismo, não sendo interessante adotar a política de preços mais flexíveis - tese principal advogada por Mansholt..$^{55}$

Outrossim, com a adesão da Grécia em 1981 e dos países ibéricos em 1986 - os quais eram predominantemente agrícolas - bem como a contínua estocagem elevada $^{56}$ e o alto custo orçamentário ${ }^{57}$ forçaram à Europa a buscar soluções mais palpáveis, mas sem desviar dos seus princípios norteadores. As tentativas iniciais englobaram a criação de cotas de produção para o açúcar e o leite em 1984, e a limitação das quantidades subsidiáveis $^{58}$.

A transformação realmente substancial ocorreu apenas em 1992, com a Reforma MacSharry. O objetivo da reforma era reduzir o excedente de produção (e consequentemente os gastos do FEOGA), por meio do corte na sustentação dos preços dos produtos agrícolas europeus. Entretanto, para que o agricultor não restasse prejudicado, este que passaria a receber ajuda para

53 CUNHA, op. cit., p. 19.

54 A crise econômica em apreço levou a retração do comércio internacional (e a consequente redução no consumo). A mesma ocorreu (i) pelo rompimento do Acordo de Bretton Woods, fazendo com que emergisse outro sistema monetário no plano internacional - o da taxa de cambio flexível, (ii) pelos choques energéticos externos provocados pelas crises do petróleo e (iii) pelas balanças comerciais negativas da América Latina. ARANHA, op. cit., p. 19; PLATERO, op. cit., 15; CANO, Wilson. Soberania e Política Econômica na América Latina. São Paulo: Editora Unesp, 2000, p. 19; EICHEGREEN, Barry. A Globalização do Capital: uma História do Sistema Monetário Internacional. Trad. Sergio Blum. São Paulo: Ed. 34, 2000, p. 183; FIORI, José Luís; TAVARES, Maria da Conceição. Poder e Dinheiro: uma economia política da globalização. $3^{\mathrm{a}}$ ed. Petrópolis: Vozes, 1997, p. 108.

55 OLIVEIRA, op. cit., p. 207.

56 Jaime L. Espinosa apresenta que no início dos anos oitenta, o valor de todas as mercadorias estocadas chegava a 2.583 milhões de Unidades Monetárias Europeias (ECU - em inglês); já em 1986 esse valor subira para expressivos 11.360 milhões de ECUs. Cf. ESPINOSA, op. cit., p. 47-48.

57 Jaime L. Espinosa expõe que os gastos do FEOGA em 1980 eram na ordem de 11.016 milhões de ECUs; já em 1987,alcançaram a marca de 22.521 milhões de ECUs, e em 1990 à soma de 26.104 milhões de ECUs. Ibidem, p. 48-49.

58 COMISSÃO EUROPEIA. History of the CAP: the crisis years II - the 1980s. s/d. Disponível em: <http://ec.europa.eu/ agriculture/cap-history/crisis-years-1980s/index_en.htm>. Acesso em 03 fev. 2015; OLIVEIRA, op. cit, p. 208. manter o seu rendimento, tendo como base o número de hectares cultivados (não guardando relação com o volume de produção). ${ }^{59}$

Por isso, Maria Clara D. Carisio ${ }^{60}$ expõe que "a mudança maior residiu na passagem de um sistema baseado essencialmente na sustentação de preços para o de sustentação de renda dos agricultores por meio de um sistema misto de preços e de ajuda direta”, ou seja, o foco deixou de ser o apoio ao mercado e passou a ser o apoio ao agricultor ${ }^{61}$. Noutros termos, essa alteração reestruturou a forma em que a União Europeia protegia o seu mercado agrícola, passando a trabalhar diretamente com o agricultor, garantindo-lhe um rendimento de base e subsídios compensatórios para manter a sua atividade, em detrimento de uma atuação sobre o mercado, em que, anteriormente, falseava os sinais do mercado distorcendo abertamente os preços dos produtos agrícolas. $^{62}$

Ademais, influenciada pela Conferência das Nações Unidas sobre o Meio Ambiente e o Desenvolvimento ocorrida em 1992 no Rio de Janeiro, mister apontar que a Reforma MacSharry também introduziu o pousio obrigatório de 15\% das terras destinadas aos cereais, oleaginosas e proteínas vegetais - terras essas que igualmente faziam jus às ajudas diretas concedidas aos produtores. ${ }^{63}$ Ao mesmo tempo, como expõe Maria Clara D. Carisio $^{64}$, os Estados deveriam "impedir o abandono total e garantir a preservação da paisagem rural" das terras deixadas inativas, o que denota o comprometimento europeu para com o desenvolvimento sustentável. ${ }^{65}$

59 OLIVEIRA, op. cit, p. 209-210; CARISIO, op. cit, p. 81-83; CARVALHO, Maria Izabel V. Condicionantes institucionais e políticos e poder de barganha nas negociações internacionais sobre agricultura. Revista Brasileira de Política Internacional, v. 49, n. 2, pp. 99-118, 2006, p. 108.

60 CARISIO, op. cit, p. 81.

61 OLIVEIRA, op. cit, p. 209.

62 ABROMOVAY, Ricardo. Subsídios e multifuncionalidade na Política Agrícola Europeia. Economia Rural, v. 40, n. 2, pp.235264, abr./jun. 2002, p. 238.

63 CUNHA, op. cit., p. 35-36 e 44; CARISIO, op. cit, p. 83-84; COMISSÃO EUROPEIA. European Farm Policy down the Years. s/d. Disponível em: <http://ec.europa.eu/agriculture/50years-of-cap/files/history/timeline_2012_en.pdf>. Acesso em 04 fev. 2015.

64 CARISIO, op. cit, p. 84.

65 Sobre o tema, cf. também: CONSELHO EUROPEU. Regulamento $\mathbf{n}^{\circ}$ 2078. 1992 (relativo à compatibilidade entre os métodos de produção agrícola e as exigências da proteção ao meio ambiente); e UNIÃO EUROPEIA. Tratado de Maastricht. 1992 Art. 130$\mathrm{R}(1)$ : A política da Comunidade no domínio do ambiente contribuirá para a prossecução dos seguintes objetivos: (i) a preservação, a pro- 
E se o escopo da dita reforma era evitar a exaustão do modelo agrícola, ela atingiu a sua finalidade, posto que os excedentes agrícolas foram sendo reduzidos ao longo dos anos ${ }^{66}$, sem que isso prejudicasse os ganhos dos agricultores e, consequentemente, culminasse no êxodo rural. ${ }^{67}$ Todavia, de acordo com Maria Clara D. Carisio ${ }^{68}$, "a introdução dos pagamentos diretos pela Reforma MacSharry não impediu a continuidade das distorções causadas pelos subsídios à produção e consequentemente à exportação", o que continuaria sendo visto como um ponto em desfavor à Europa nas negociações da Rodada do Uruguai que se desenrolavam desde 1986.

E, precisamente nesse âmbito, inicia-se uma nova proposta de reforma, a qual se concretiza em $1997 \mathrm{com}$ a apresentação da Agenda $2000^{69}$. Afinal, conforme María Marcele A. Aranha, tomando por base a

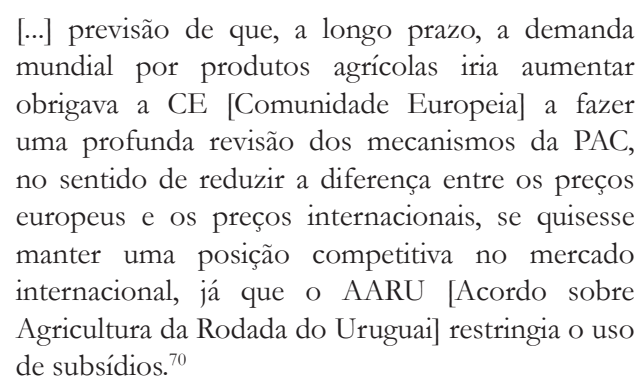

Em vista disso, a Agenda 2000 cria o conceito de multifuncionalidade da atividade agrícola para "justificar" os pagamentos diretos realizados ao agricultor. ${ }^{71}$ Isso,

teção e a melhoria da qualidade do ambiente; [...] (iii) a utilização prudente e racional dos recursos naturais; [...].

66 Arlindo Cunha apresenta essa diminuição em números. Os excedentes de cereais, por exemplo, diminuíram significativamente: 14.379.000 toneladas em 1990 para 1.209.000 toneladas em 1996; já a manteiga, de 333.000 toneladas em 1990 para 14.000 em 1995. Inclusive, faz-se imperioso destacar que entre 1995-1996 a quase exaustão dos cereais levou a Comissão a impor um imposto à exportação dos mesmos, na tentativa de impedir a sua falta no mercado interno - medida essa criticada por parte dos produtores. CUNHA, op. cit., p. $56-57$.

67 ARANHA, op. cit., p. 105-108.

68 CARISIO, op. cit, p. 98.

69 COMISSÃO EUROPEIA. Agenda 2000: for a stronger and wider union. 1997. Disponível em: <http://ec.europa.eu/agriculture/cap-history/agenda-2000/com97-2000_en.pdf>. Acesso em 05 fev. 2015.

70 ARANHA, op. cit., p. 109. No mesmo sentido: CUNHA, op. cit., p. 83-84; LOYAT; PETIT, op. cit, p. 29.

71 ABROMOVAY, op. cit., p. 238; POTTER, Clive; BURNEY, Jonathan. Agricultural multifunctionality in the WTO: legitimate non-trade concern or disguised protectionism? Journal of Rural Studies, v. 18, n. 1, p. 35-47, 2002, p. 36; SWINBANK, Alan. CAP Reform and the WTO: compatibility ad developments. European Review of Agricultural Economics, v. 26, n. 3, pp.389-407, 1999. Para uma visão contrária a multifuncionalidade a nível internacional pois, a função desempenhada pelo produtor rural na sociedade iria muito mais além do que a produção de alimentos, abrangendo também a prestação de serviços socioambientais (de preservação ao meio ambiente), o que justificaria a (re)compensa(ção) percebida. ${ }^{72}$ Inclusive, essa medida deu ensejo a inserção de uma condição para a realização dos pagamentos, qual seja, de que as exigências ambientais comunitárias (e nacionais, caso os Estados-membros assim estipulassem) fossem cumpridas, sendo, por isso, chamada de eco-condicionalidade. ${ }^{73}$

Não obstante, a Agenda, também, pretendia debater os impactos do alargamento da União Europeia aos países centrais e do leste ${ }^{74}$ à PAC, já que "se pensava na possibilidade dos novos membros trazerem consigo novamente os excedentes agrícolas e ocasionarem uma explosão nas despesas", como exprime Maxime Habran $^{75}$. Nesse aspecto, a Agenda previa a criação de um Programa de Acesso para a Agricultura e Desenvolvimento Rural (SAPARD - em inglês), disponibilizando a quantia de $€ 520$ milhões para que os países pudessem preencher os requisitos, sem que isso se transformasse em um retrocesso à PAC. ${ }^{76}$

Entretanto, como expôs Maria Marcele A. Aranha ${ }^{77}$, se a finalidade da Agenda era justamente "preparar a PAC para enfrentar os desafios do novo milênio, sobretudo, a expansão dos mercados agrícolas mundiais", não se logrou êxito com a implantação da mesma. ${ }^{78}$ Afora a "desculpa" da multifuncionalidade, a diminuição do apoio concedido aos agricultores aprovada consistia apenas na possibilidade de os países adotarem-se um teto máximo de pagamento. ${ }^{79} \mathrm{E}$, no que diz respeito ao

("multilateral do comércio"), v. MESQUITA, Paulo E. Multifuncionalidade e Preocupações Não-Comerciais. Brasília: FUNAG, 2005, p. 273-279.

72 ARANHA, op. cit., p. 113; CUNHA, op. cit., p. 103.

73 Ibidem, p. 112; CONSELHO EUROPEU. Regulamento n. 99/1259. 1999; UBACH, Andres M. Cosillas. Regimen Juridico de la Propiedad Agraria sujeta a la nueva PAC. Barcelona: Atelier, 2009 , p. 69.

74 Trata-se de Polônia, Hungria, Republica Checa, Eslovênia, Estônia. Eslováquia, Romênia, Bulgária, Letônia e Lituânia; e na sequência, Malta e Chipre.

75 HABRAN, Maxime. Le verdissement de la polirique agricole commune (PAC): analyse d'une (r)évolution. Cahiers de Sciences politiques de l'ULg, Liege, n. 24, pp. 1-11, 2012, p. 3.

76 Cf. CONSELHO EUROPEU. Regulamento n. 99/1268. 1999; CONSELHO EUROPEU. Regulamento n. 00/2222. 2000.

77 ARANHA, op. cit., p. 109.

78 Essa medida também restou conhecida como modulação (CUNHA, op. cit., p. 91-92).

79 ARANHA, op. cit., p. 112. 
alargamento, a Agenda tornou os novos países não elegíveis ao financiamento pleno previsto na PAC quando do seu ingresso na união ${ }^{80}$, aprovando a manutenção da dimensão e composição orçamentária da PAC à época ${ }^{81}$.

Conquanto a sua aplicação fosse projetada para ocorrer entre 2000-2006, no ano de 2003, o Conselho requereu a Comissão um relatório acerca das despesas agrícolas, onde sugerisse propostas para a adequação da PAC. ${ }^{82}$ A resposta da Comissão veio em formato de uma nova reforma no ano de 2003 - a Reforma Fischler.

A referida reforma impunha novas bases para o repasse das ajudas diretas ao agricultor. A fim de que esse recebesse, três requisitos deveriam ser cumpridos: (i) a desvinculação do suporte financeiro à produção, sendo pagas em cota única por hectare explorado com base em seus ganhos do biênio 2000-2002 ${ }^{83}$; (ii) a manutenção da eco-condicionalidade, considerando não apenas manutenção das áreas verdes, mas também a saúde da população e a animal; e (iii) a redução progressiva e obrigatória dos pagamentos diretos aos produtores, realizadas em módulos de 3\% (2005), 4\% (2006) e 6\% (2007-2012), mais conhecida como degressividade. ${ }^{84}$

Com essas modificações, a Reforma Fischler foi considerada um grande avanço para a PAC. Com essa reestruturação, as distorções mercadológicas diminuíram em virtude da maior transparência quanto aos pagamentos realizados ${ }^{85}$; os gastos com a PAC foram reduzidos em $€ 2$ bilhões entre 2005-2013, o que corresponde a 10\% do orçamento, mesmo com os novos alargamentos que

80 SILVA, Antônio M. História da Unificação Europeia Comunitária: 1945-2010. Coimbra: Universidade de Coimbra, 2010, p. $243-244$

81 QUELHAS, José Manuel S. A Agenda 2000 e o sistema de financiamento da União Europeia. Temas de Integração, v. 3, n. 5, pp. 53-109, 1998, p. 102-103.

82 CUNHA, op. cit., p. 133.

83 Os novos Estados oriundos do alargamento também estavam inseridos nessa reforma, recebendo a partir de 2004 a quantia referente a $25 \%$ dos Estados-membros da 'Europa dos 15', sujeitas a aumento anual na ordem de 10\%. CUNHA, op. cit., p. 135.

84 CARISIO, op. cit, p. 156-162; HABRAN, op. cit., p. 6-7; NAVARRATE, Donato Fernandez. Fundamentos Económicos de la Unión Europea. Madrid: Thomson, 2007, p. 275; CONSELHO EUROPEU. Regulamento n. 03/1782. 2003; LEIBOVITCH, Emilie H. Food Safety Regulation in the European Union. Texas International Law Journal. v. 43, pp. 429-452, 2007-2008, p. 450. 85 BIANCHI, op. cit, p. 4; COMISSÃO EUROPEIA. Commissioner Fischler on Agricultural Reform: 2003 is a year of decisions. Notícia veiculada em 16 jan. 2003. Disponível em: <http:// europa.eu/rapid/press-release_IP-03-65_en.htm?locale=en $>$. Acesso em 06 fev. 2015. ocorreram nos anos $2000^{86}$; e o produtor rural modernizou-se, conscientizando-se quanto à importância da paisagem rural e reconhecendo seu papel na sociedade, levando, até mesmo, ao aumento da população do cam$\mathrm{po}^{87}$.

Pequenas mudanças relativas a essa reforma ocorreram em 2008, quando da aprovação de um acordo político no âmbito do Conselho com vistas a realizar um “check-up” na saúde da PAC. As alterações incluíam a retirada de restrições na produção em virtude da crescente demanda em alguns setores como arroz, leite e carne de porco; e uma maior desvinculação dos pagamentos, na tentativa de conceder ao produtor maior flexibilidade frente ao mercado, sobretudo, em função das mudanças climáticas e outros desafios ambientais como a falta de água e a proteção da biodiversidade. ${ }^{88}$

Contudo, como o "plano" realizado pela Reforma Fischler vigoraria até 2013, nessa data, começou-se a discutir uma nova reforma, cuja entrada em vigor ocorreu em janeiro de 2014. Essa reforma, seguindo as mesmas linhas das discussões de 2008, tem como intuito direcionar os pagamentos direitos principalmente à adoção de práticas sustentáveis e à proteção ambiental.

Isso significa dizer que a PAC 2014, consciente dos desafios ambientais enfrentados no século XXI, reestruturaria a política agrícola europeia de modo a trabalhar mais diretamente com a terra, em detrimento do agricultor em si, adotando uma nova vertente de funcionamento - a terceira desde a sua criação. ${ }^{89} \mathrm{~A}$ intenção atual é de realizar pagamentos diretos e financiar programas destinados a responder problemas alheios à atividade agrícola em $\mathrm{si}^{90}$, como (i) incentivar a transfe-

86 CARISIO, op. cit, p. 174-175.

87 PIRZIO-BIROLI, Corrado. $\mathrm{Na}$ inside perspective on the Political Economy of the Fischler Reforms. In: SWINNEN, Johan. F. The Perfect Storm: the political economy of the Fischler reforms of the common agricultural policy. Brussels: Centre for European Studies, 2008, p. 124-125; COMISSÃO EUROPEIA. European Farm Policy..., op. cit, p. 1.

88 UBACH, op. cit., p. 71-73; CONSELHO EUROPEU. Regulamento n. 72. 2009; CONSELHO EUROPEU. Regulamento n. 73. 2009; CONSELHO EUROPEU. Regulamento n. 74. 2009; COMISSÃO EUROPEIA. History of the CAP: The 2008 CAP "Health Check". s/d. Disponível em: < http:/ / ec.europa.eu/agriculture/cap-history/health-check/index_en.htm>. Acesso em 03 fev. 2015.

89 COMISSÃO EUROPEIA. Overview of CAP Reform: 20142020. Agricultural Policy Perspectives Brief, n. 5, pp. 1-10, dec. 2013.

90 Problemas como o decréscimo (ou no mínimo a estagnação) do crescimento econômico, a volatilidade dos preços, os custos de 
rência de conhecimento para a adoção de práticas rurais "mais verdes"; (ii) promover a competitividade agrícola de forma sustentável; (iii) fomentar a criação de redes de alimentos; (iv) preservar os ecossistemas, oportunizando uma agricultura verde-eficiente; e (v) exercitar a inclusão social. ${ }^{91}$

Os planos, portanto, são de manter os pagamentos diretos aos agricultores europeus, destinando cerca de $€ 277.851$ bilhões de um total de $€ 362.787$ disponíveis à $\mathrm{PAC}$ (o que corresponde a 37,8\% do orçamento comunitário) a essa atividade. ${ }^{92}$ Para os investimentos no setor rural, o total destinado está estimado em €84.936 bilhões. ${ }^{93}$ Com esses montantes, de acordo com Nádia Franco $^{94}$, espera-se que nenhum Estado-membro "receba menos de $75 \%$ da média europeia" e que nenhum agricultor receba "menos de $60 \%$ da média nacional", estando esse, inclusive, respaldado por um sistema de travamento, o qual "assegura que as [suas] perdas [...] não sejam superiores a 30\%".

Logo, nota-se que, ao longo de 60 anos, a PAC demonstrou voltar-se a proteção do mercado interno, do produtor rural e, mais recentemente, ao desenvolvimento rural sustentável. Para tanto, age focada nos seus interesses, a fim de que o cenário dos primeiros cinquenta anos do século XX não se repitam em âmbito europeu - atitude essa que se reflete na privilegiada posição ocupada pela União Europeia no contexto internacional de importação e exportação de produtos primários ${ }^{95}$.

produção, o aumento demográfico, a realocação de investimentos, o deterioramento do solo e da água e a própria insegurança alimentar mundial. Ibidem, p. 2; BIANCHI, op. cit, p. 4;

91 COMISSÃO EUROPEIA. Overview of CAP Reform..., op. cit., p. 7-9; CONSELHO EUROPEU. Regulamento n. 1305. 2013; CONSELHO EUROPEU. Regulamento n. 1306. 2013; CONSELHO EUROPEU. Regulamento n. 1307. 2013; CONSELHO EUROPEU. Regulamento n. 1308. 2013; COMISSÃO EUROPEIA. History of the CAP: the CAP post-2013. s/d. Disponível em: <http://ec.europa.eu/agriculture/cap-history/post2013/index_en.htm>. Acesso em 03 fev. 2015

92 COMISSÃO EUROPEIA. Overview of CAP Reform..., op. cit., p. 3.

93 Ibidem, loc. cit.

94 FRANCO, Nádia. União Europeia aprova nova Política Agrícola Comum. Agência Brasil. Notícia veiculada em 16 dez. 2013. Disponível em: <http://memoria.ebc.com.br/agenciabrasil/noticia/2013-12-16/uniao-europeia-aprova-nova-politica-agricola-comum>. Acesso em 06 fev. 2015.

95 "A União Europeia é o maior exportador de produtos agrícolas do mundo", tendo sido responsável, em 2005, por 20\% das exportações, equivalendo a US\$ 79 bilhões. "A União Europeia também é o maior importador de produtos agrícolas", movimentando, em 2006, cerca de US\$ 85 bilhões. O'CONNOR, Bernard. The
Apesar disso, tal protecionismo adotado desfavorece a cooperação internacional, especialmente no que diz respeito ao desenvolvimento do comércio internacional. Inclusive, esse posicionamento destoa da "retórica liberal" adotada pelos Estados em 1944 em Bretton Woods, de modo que se monstra muito mais inclinado à manutenção do status quo no que diz respeito a mercado internacional (já que dominado largamente pela União Europeia), do que efetivamente a formação de um espaço voltado à troca aberta de mercadorias, pautadas na especialidade produtiva, "pode[ndo] causar, a longo prazo, efeitos perversos à soberania alimentar e ao crescimento econômico e agroindustrial" de outras nações. ${ }^{96}$

Por isso, a PAC tem sido alvo de severas críticas desde a Rodada do Uruguai, até a presente Rodada de Doha da Organização Mundial do Comércio, tomando sempre posições mais defensivas do que ofensivas nas argumentações por um comércio mais equilibrado (livre de distorções ou barreiras tarifárias e não tarifárias) ${ }^{97}, \mathrm{o}$ que poderia culminar numa nova modificação no futuro próximo se não fosse a alteração almejada - a diminuição da proteção do mercado agrícola - contrária aos próprios propósitos originários da PAC.

\section{Considerações finais}

Este artigo tinha como objetivo central delinear o surgimento da Política Agrícola Comum da União Europeia, destacando as modificações ocorridas ao longo dos anos frente aos novos arranjos socioeconômicos regionais e mundiais. Por conseguinte, vislumbrou-se, justamente, a importância que o setor agrícola possui para o contexto integracionista europeu, sendo consi-

Food Crisis and the role of EC's Common Agricultural Policy. In: KARAPINAR, Baris; HABERLI, Christian. Food Crisis and the WTO. Cambridge: Cambridge University Press, 2010, p.192.

96 GOMES, Natália Fernanda. A regulação internacional dos subsídios agrícolas: a contemporaneidade do paradigma realista para a compreensão do sistema de comércio agrícola internacional vigente. Revista de Direito Internacional, Brasília, v. 10, n.1, pp. 43-55, 2013, p. 46-46, 49, 53- 54 (cit.).

97 O'CONNOR, op. cit., p. 216; CARVALHO, Leonardo A. O Futuro da Agricultura. In: BARRAL, Welber. O Brasil e a OMC. Florianópolis: Ed. Diploma Legal, 2000, p. 231-232; CEDRO, Rafael Cedro. Princípios da política brasileira de segurança alimentar e o acordo sobre agricultura da OMC. Prismas: Direito, Políticas Públicas e Mundialização, Brasília, v. 5, n. 2, pp. 255-280, jul./ dez. 2008, p. 264-268. 
derada uma de suas principais políticas. Afinal, se para a garantia da paz era imperioso fomentar a integração e sabendo que a insegurança alimentar era um problema que poderia prejudicar esse objetivo, a inclusão da agricultura nas estruturas da comunidade europeia era inevitável.

Todavia, viu-se que, uma vez atingidos esses objetivos (de segurança alimentar), contando inclusive com um grande excedente, o enfoque passou a ser outro: o combate ao alto custo orçamentário. Isso, pois, a crescente necessidade de se intervir no mercado para comprar ou estocar o excedente, e os subsídios fornecidos à exportação de mercadorias primárias, passaram a ser um grande ponto de debate entre os Estados-membros, fomentando as suas transformações com o passar do tempo.

E a grande modificação, de não mais pagar diretamente os agricultores pelo volume de produção, mas sim subsidiar a atividade em si, fomentando as políticas ecologicamente equilibradas foi vista como um grande avanço, tanto internamente, como internacionalmente, uma vez que não apenas reduziu os gastos com o setor, como também (teoricamente) insere maior transparência nas atividades agrícolas europeias.

Outrossim, tem-se que essas modificações deveriam preocupar-se mais com as regras do comércio internacional, uma vez que as medidas contidas na PAC ainda são conflitantes com as regras desse ramo do Direito Internacional, justamente por promoverem o produto(r) europeu. Por isso, nas diversas rodadas de negociação da OMC, o bloco não propõe medidas proativas, senão apenas defensivas quando questionado por outros membros, tal como o Brasil.

Dessa feita, mesmo que as relações comerciais internacionais evoluam, o que se vislumbra é que a UE sempre dará prioridade ao mercado intrabloco, sendo essa uma política já enraizada no seio da comunidade desde 1957 e que parece não ser modificável, mesmo com as constantes reformas na PAC. Quer isto dizer que a UE parece estar disposta a continuar inserido previsões que corrompam a lógica do mercado internacional, tal como aquelas geradas pelos subsídios fornecidos aos agricultores (seja em pagamentos diretos ou direcionados ao produtor), já que o seu objetivo, de fato, ainda é a garantia da soberania alimentar.

Numa palavra, a partir das modificações estudadas, parece evidente que as alterações na PAC nunca serão, realmente, alinhadas às do comércio internacional (situadas no âmbito da OMC), em virtude dos próprios objetivos dessa política quando da sua constituição, sendo, portanto, inevitável que países que tenham uma economia com base na agricultura - como o Brasil sintam os efeitos protecionistas da Europa quando essa assim desejar.

\section{REFERÊNCIAS BIBLIOGRÁFICAS}

ABELLÁN, Aurelio C. Las Regiones del Sistema Mundo. Murica: Universidad de Murica, 1993.

ABROMOVAY, Ricardo. Subsídios e multifuncionalidade na Política Agrícola Europeia. Economia Rural, v. 40, n. 2, pp.235-264, abr./jun. 2002.

ADAM, Valérie. La reforme de la Politique Agricole Commune de L'Union Europeenne. Paris: Editions L'Harmattan, 2001.

ALENCAR, Álvaro Gurgel de. Do conceito estratégico de segurança alimentar ao plano de ação da FAO para combater a fome. Revista Brasileira de Política Internacional, Brasília, v. 44, n. 1, pp. 137-144, 2001.

ARANHA, Maria Marcele A. A Política Agrícola Comum e a Disciplina do Apoio Interno do Acordo sobre Agricultura da Rodada do Uruguai. Coimbra: Coimbra ed., 2007.

BARRAL, Welber. O Brasil e a OMC. Florianópolis: Ed. Diploma Legal, 2000.

BAUMANN, Renato; CANUTO, Otaviano; GONÇALVES, Reinaldo. Economia Internacional: teoria e experiência brasileira. Rio de Janeiro: Campus, 2004.

BIANCHI, Danielle. La Politique Agricole Commune. Bruxelles: Bruylant, 2006.

BOHKLE, Marcelo. O processo de Integração Regional e a Autonomia do seu Ordenamento Jurídico, 2002, 264 fls. Dissertação - Mestrado em Direito. Florianópolis: Universidade Federal de Santa Catarina, 2002.

CAMPOS, João Mota de. Manual de Direito Comunitário. $2^{a}$ ed. Curitiba: Juruá, 2013.

CANO, Wilson. Soberania e Política Econômica na América Latina. São Paulo: Editora Unesp, 2000.

CARISIO, Maria Clara D. A Política Agrícola Co- 
mum da União Europeia e seus Efeitos Sobre os Interesses Brasileiros nas Negociações Internacionais Sobre Agricultura. Brasília: FUNAG, 2006.

CARMO, Luis Antônio A. A vertente aduaneira da Política Agrícola Comum. In: TEIXEIRA, Glória. Direito Rural (coord.). Porto: Vida Econômica, 2013.

CARNEIRO, Cynthia S. O Direito da Integração Regional. Belo Horizonte: Del Rey, 2007.

CARVAlHO, Maria Auxiliadora. Políticas Públicas e Competitividade de Agricultura. Revista de Economia Política, São Paulo, v.21, n. 1, pp. 117-140, jan./ mar. 2001.

CARVALHO, Maria Izabel V. Condicionantes institucionais e políticos e poder de barganha nas negociações internacionais sobre agricultura. Revista Brasileira de Política Internacional, v. 49, n. 2, pp. 99-118, 2006.

CARVALHO, Leonardo A. O Futuro da Agricultura. In: BARRAL, Welber. O Brasil e a OMC. Florianópolis: Ed. Diploma Legal, 2000.

CEDRO, Rafael Cedro. Princípios da política brasileira de segurança alimentar e o acordo sobre agricultura da OMC. Prismas: Direito, Políticas Públicas e Mundialização, Brasília, v. 5, n. 2, pp. 255-280, jul./ dez. 2008.

COMISSÃO EUROPEIA. Agenda 2000: for a stronger and wider union. 1997. Disponível em: <http:// ec.europa.eu/agriculture/cap-history/agenda-2000/ com97-2000_en.pdf>. Acesso em 05 fev. 2015.

COMISSÃO EUROPEIA. Commissioner Fischler on Agricultural Reform: 2003 is a year of decisions. Notícia veiculada em 16 jan. 2003. Disponível em: $<$ http:/ / europa.eu/rapid/press-release_IP-03-65_ en.htm?locale=en $>$. Acesso em 06 fev. 2015.

COMISSÃO EUROPEIA. European Farm Policy down the Years. s/d. Disponível em: <http:// ec.europa.eu/agriculture/50-years-of-cap/files/history/timeline_2012_en.pdf>. Acesso em 04 fev. 2015.

COMISSÃO EUROPEIA. History of the CAP: The 2008 CAP "Health Check". s/d. Disponível em: $<$ http:/ /ec.europa.eu/agriculture/cap-history/healthcheck/index_en.htm>. Acesso em 03 fev. 2015.

COMISSÃO EUROPEIA. History of the CAP: the CAP post-2013. s/d. Disponível em: <http:// ec.europa.eu/agriculture/cap-history/post-2013/in- dex_en.htm>. Acesso em 03 fev. 2015.

COMISSÃO EUROPEIA. History of the CAP: the crisis years I - the 1970s. s/d. Disponível em: < http:/ / ec.europa.eu/agriculture/cap-history/crisis-years1970s/index_en.htm>. Acesso em 03 fev. 2015.

COMISSÃO EUROPEIA. History of the CAP: the crisis years II - the 1980s. s/d. Disponível em: < http:/ / ec.europa.eu/agriculture/cap-history/crisis-years1980s/index_en.htm>. Acesso em 03 fev. 2015.

COMISSÃO EUROPEIA. Overview of CAP Reform: 2014-2020. Agricultural Policy Perspectives Brief, n. 5, pp. 1-10, dec. 2013.

CONSELHO EUROPEU. Regulamento n. 1305. 2013.

CONSELHO EUROPEU. Regulamento n. 1306. 2013.

CONSELHO EUROPEU. Regulamento n. 1308. 2013.

CONSELHO EUROPEU. Regulamento n. 00/2222. 2000.

CONSELHO EUROPEU. Regulamento n. 03/1782. 2003.

CONSELHO EUROPEU. Regulamento n. 1307. 2013.

CONSELHO EUROPEU. Regulamento n. 72. 2009.

CONSELHO EUROPEU. Regulamento n. 73. 2009.

CONSELHO EUROPEU. Regulamento n. 74. 2009.

CONSELHO EUROPEU. Regulamento n. 99/1259. 1999.

CONSELHO EUROPEU. Regulamento $\mathrm{n}^{\circ} 2078$. 1992.

CUNHA, Arlindo. A Política Agrícola Comum na Era da Globalização. Coimbra: Almedina, 2004.

EICHEGREEN, Barry. A Globalização do Capital: uma História do Sistema Monetário Internacional. Trad. Sergio Blum. São Paulo: Ed. 34, 2000.

ESPINOSA, Jaime L. La Nueva Política Agraria de la Unión Europea. Madrid: Ediciones Encuentro, 1998.

FERNANDES, José Pedro. Elementos de Economia Política Internacional. $2^{\mathrm{a}}$ ed. Coimbra: Almedina, 2012. 
FIORI, José Luís; TAVARES, Maria da Conceição. Poder e Dinheiro: uma economia política da globalização. $3^{a}$ ed. Petrópolis: Vozes, 1997.

FRANCO, Nádia. União Europeia aprova nova Política Agrícola Comum. Agência Brasil. Notícia veiculada em 16 dez. 2013. Disponível em: < http://memoria.ebc. com.br/agenciabrasil/noticia/2013-12-16/uniao-europeia-aprova-nova-politica-agricola-comum $>$. Acesso em 06 fev. 2015.

GOMES, Natália Fernanda. A regulação internacional dos subsídios agrícolas: a contemporaneidade do paradigma realista para a compreensão do sistema de comércio agrícola internacional vigente. Revista de Direito Internacional, Brasília, v. 10, n.1, pp. 43-55, 2013.

HABRAN, Maxime. Le verdissement de la polirique agricole commune (PAC): analyse d'une (r)évolution. Cahiers de Sciences politiques de l'ULg, Liege, n. 24, pp. 1-11, 2012.

HOBSBAWN, Eric. The Age of Extremes: a history of the world 1914-1991. New York: vintage books, 1994.

JAEGER JUNIOR, Augusto. Mercados Comum e Interno e Liberdades Econômicas Fundamentais. Curitiba: Juruá, 2010.

JUNQUEIRA, Bráulio. A institucionalização política da União Europeia. Coimbra: Almedina, 2008.

KANT, Immanuel. A Metafísica dos Costumes. Trad. Edson Bini. São Paulo: Edipro, 2003.

KOZOLCHYK, Boris. Comparative Commercial Contracts: law, culture and economic development. St. Paul: West Academic Pub., 2014.

LAUREANO, Abel; RENTO, Altina. Uma sumária radiografia da política comum das pescas da União Europeia. Revista de Direito Internacional, Brasília, v. 9, n. 3, pp. 71-90, 2012.

LEIBOVITCH, Emilie H. Food Safety Regulation in the European Union. Texas International Law Journal. v. 43, pp. 429-452, 2007-2008.

LOYAT, Jacques; PETIT, Yves. La Politique Agricole Commune (PAC): une politique en mutation. $3 \mathrm{a}$ ed. Paris: La Documentation Française, 2008.

MESQUITA, Paulo E. Multifuncionalidade e Preocupações Não-Comerciais. Brasília: FUNAG, 2005.
MOLINA IBAÑEZ, M.; RODRIGUES POSE, A. Transformaciones Agrarias em la Europa Comunitária. Salamanca: Universidad de Salamanca, 1992, apud OLIVEIRA, Maria Odete. União Europeia: processos de integração e mutação. Curitiba: Juruá, 2005.

NAVARRATE, Donato Fernandez. Fundamentos Económicos de la Unión Europea. Madrid: Thomson, 2007.

O'CONNOR, Bernard. The Food Crisis and the role of EC's Common Agricultural Policy. In: KARAPINAR, Baris; HABERLI, Christian. Food Crisis and the WTO. Cambridge: Cambridge University Press, 2010.

OLIVEIRA, Maria Odete. União Europeia: processos de integração e mutação. Curitiba: Juruá, 2005.

PARLAMENTO EUROPEU. Fichas Técnicas sobre a União Europeia: Primeiro pilar da PAC. Nota veiculada em mar. 2014. Disponível em: <http://www. europarl.europa.eu/aboutparliament/pt/displayFtu. html?ftuId=FTU_5.2.4.html>. Acesso em 03 fev. 2015. PIRZIO-BIROLI, Corrado. Na inside perspective on the Political Economy of the Fischler Reforms. In: SWINNEN, Johan. F. The Perfect Storm: the political economy of the Fischler reforms of the common agricultural policy. Brussels: Centre for European Studies, 2008.

PLATERO, Roberto Velasquez. Inversión y Mecanismos para la Movilizacion de Recursos Financieros para la Agricultura. San José: Inst. Interamericando de Coop. Para la Agricultura, 1989.

POTTER, Clive; BURNEY, Jonathan. Agricultural multifunctionality in the WTO: legitimate non-trade concern or disguised protectionism? Journal of Rural Studies, v. 18, n. 1, p. 35-47, 2002.

QUELHAS, José Manuel S. A Agenda 2000 e o sistema de financiamento da União Europeia. Temas de Integração, v. 3, n. 5, pp. 53-109, 1998.

SANTOS, Francis. Perspectiva para a soberania alimentar brasileira. In: DAL SOGLIO, Fábio; KUBO, Rumi Regina (coords.). Agricultura e Sustentabilidade. Porto Alegre: Editora da UFRGS, 2009.

SILVA, Antônio M. História da Unificação Europeia Comunitária: 1945-2010. Coimbra: Universidade de Coimbra, 2010. 
SILVA, Daniel P.; FERREIRA, Grace K. A política Agrícola Comum da União Europeia. Fronteira. Belo Horizonte, v. 7, n. 14, pp.65-76, 2008.

SWINBANK, Alan. CAP Reform and the WTO: compatibility ad developments. European Review of Agricultural Economics, v. 26, n. 3, pp.389-407, 1999.

TEO, Carla Rosane Paz; GALLINA, Lucinada S. Segurança Alimentar e Ambiente: a sustentabilidade como área de convergência. In: SÁ, Clodoaldo de; FERRETI, Fátima; BUSATO, Maria Assunta. Ensaios Contemporâneos em Saúde. Chapecó: Argos, 2013.

U.S. DEPARTMENT OF AGRICULTURE. Indices of Agriculture Production in Western Euro- pe - 1650-1968. Washington D.C.: US Department of Agriculture, 1969. Disponível em: <https://archive.org/stream/indicesofagricul266unit\#page/n1/ mode/2up >. Acesso em: 02 fev. 2015.

UBACH, Andres M. Cosillas. Regimen Juridico de la Propiedad Agraria sujeta a la nueva PAC. Barcelona: Atelier, 2009.

UNIÃO EUROPEIA. Tratado Constitutivo da Comunidade Econômica Europeia. 1957.

UNIÃO EUROPEIA. Tratado de Maastricht. 1992.

VEIGA, José Eli da. O Desenvolvimento Agrícola: uma visão histórica. $2^{\mathrm{a}}$ ed. São Paulo: Edusp, 2007. 
Para publicar na Revista de Direito Internacional, acesse o endereço eletrônico www.rdi.uniceub.br ou www.brazilianjournal.org.

Observe as normas de publicação, para facilitar e agilizar o trabalho de edição. 